\title{
Hydrogen cyanide in the headspace of oral fluid and in mouth-exhaled breath
}

\section{Chen, W.}

2014-06

Chen , W , Metsala , M , Vaittinen , O \& Halonen , L 2014, ' Hydrogen cyanide in the headspace of oral fluid and in mouth-exhaled breath ' , Journal of Breath Research , vol. 8 , no. 2 , 027108 . https://doi.org/10.1088/1752-7155/8/2/027108

http://hdl.handle.net/10138/152833

https://doi.org/10.1088/1752-7155/8/2/027108

acceptedVersion

Downloaded from Helda, University of Helsinki institutional repository.

This is an electronic reprint of the original article.

This reprint may differ from the original in pagination and typographic detail.

Please cite the original version. 


\title{
Hydrogen cyanide in the headspace of oral fluid and in mouth-exhaled breath
}

\author{
W Chen, M Metsälä, O Vaittinen and L Halonen \\ Laboratory of Physical Chemistry, Department of Chemistry, PO Box 55 (A.I. \\ Virtasen aukio 1), FIN-00014 University of Helsinki, Finland \\ E-mail: markus.metsala@helsinki.fi
}

\begin{abstract}
Mouth-exhaled hydrogen cyanide ( $\mathrm{HCN})$ concentrations have previously been reported to originate from the oral cavity. However, a direct correlation between the HCN concentration in oral fluid and in mouth-exhaled breath has not been explicitly shown. In this study, we set up a new methodology to simultaneously measure HCN in the headspace of oral fluid and in mouth-exhaled breath. Our results show that there is a statistically significant correlation between stimulated oral fluid $\mathrm{HCN}$ and mouth-exhaled $\mathrm{HCN}\left(r_{s}=0.76, p<0.001\right)$. This confirms that oral fluid is the main contributor to mouth-exhaled HCN. Furthermore, we observe that after the application of an oral disinfectant, both the stimulated oral fluid and mouth-exhaled $\mathrm{HCN}$ concentrations decrease. This implies that HCN production in the oral cavity is related to bacterial and/or enzymatic activity.
\end{abstract}

\section{Introduction}

Hydrogen cyanide $(\mathrm{HCN})$ is a lethally toxic volatile compound, which is released in industrial processes [1], vehicle exhausts [2] and fire fumes [3]. In nature, $\mathrm{HCN}$ can be released by degradation of cyanogenic glycosides in plants [4] or by enzymatic activity of cyanogenic bacteria [5]. Low concentrations of $\mathrm{HCN}$ are detected in the human body due to endogenous biological processes [6,7] and environmental exposure. To evaluate the systemic cyanide level, the focus has been on developing fast and reliable methods to measure the cyanide concentration in blood [8-10]. In addition to blood cyanide, exhaled breath HCN was measured first time by Lundquist et al [11]. Pseudomonas aeruginosa was found to be one of the few bacteria, which can produce cyanide [5]. Hence, cyanide is a potential biomarker of $P$. aeruginosa lung infection, which is linked to e.g. cystic fibrosis. It has been found that chronic lung infection by $P$. aeruginosa is the major cause of morbidity and mortality in cystic fibrosis patients [12].

Current diagnosis methods for $P$. aeruginosa lung infection include sputum sampling, bronchoalveolar lavage (BAL), cough swab sampling, and blood antibody methods $[13,14]$. These methods are invasive and in some cases unreliable. It would be beneficial to develop a non-invasive test, which could detect $P$. aeruginosa lung infection easily and reliably. Exhaled breath HCN has been proposed to be a biomarker for $P$. aeruginosa lung infection of cystic fibrosis patients [15]. It was shown that after the culturing of sputum and cough swabs of $P$. aeruginosa lung infected patients, the HCN concentration in the headspace of $P$. aeruginosa-positive samples is significantly higher than that of other samples [16]. Elevated concentrations of cyanide ion in the sputum of $P$. aeruginosa lung 
infected patients were also found without culturing the samples $[17,18]$. It was further demonstrated that mouth-exhaled HCN level in children with cystic fibrosis and $P$. aeruginosa lung infection is higher than in children with asthma [19]. However, in adult patients with $P$. aeruginosa lung infection, the mouth-exhaled HCN concentration is not significantly higher than that in non-infected adults [20]. On the other hand, the nose-exhaled HCN concentration in $P$. aeruginosa lung infected adult patients is significantly elevated [20].

Mouth-exhaled HCN from healthy people was first studied by selected ion flow tube mass spectrometry (SIFT-MS) [21-23]. It was found that even healthy adults without $P$. aeruginosa lung infection generate detectable amount of mouth-exhaled $\mathrm{HCN}$, ranging from $1 \mathrm{ppb}$ to $62 \mathrm{ppb}$ $[15,21,22]$. HCN was also detected in mouth-exhaled breath of healthy adults by cavity ring down spectroscopy (CRDS) in bag sampling, within the range from 1.7 to $13.5 \mathrm{ppb}$ [24]. Interestingly, among children aged 7-18 without $P$. aeruginosa infection, very little mouth-exhaled HCN was detectable (Interquartile range 0.0-4.8 ppb) [23]. Additionally, Wang et al demonstrated that the mouth-exhaled HCN in healthy people is mainly generated in the oral cavity [25]. This was confirmed by Schmidt et al, who also observed a higher HCN concentration in mouth-exhaled breath than in nose-exhaled breath [26]. To avoid the effect of the oral production, nose-exhaled HCN was suggested for the diagnosis of $P$. aeruginosa lung infection [20]. However, nose-exhaled breath is still partly affected by mouth-exhaled breath. It has been shown that there is a moderate correlation between nose-exhaled HCN and mouth-exhaled HCN [26]. It would be beneficial to understand how mouthexhaled $\mathrm{HCN}$ is generated in order to minimize the influence of mouth-exhaled HCN on nose-exhaled $\mathrm{HCN}$.

Since the oral cavity is the production site of mouth-exhaled HCN [25] and oral fluid was suggested to be the origin of mouth-exhaled HCN [11], we seek to further clarify how the change of HCN in oral fluid influences mouth-exhaled HCN. Here, we differentiate between oral fluid and saliva. Saliva refers to the fluids secreted by the salivary glands. For example, sublingual saliva refers to the fluid secreted by the sublingual gland. Oral fluid includes not only saliva, but also fluid secreted by the gingival crevices and other species present in the oral cavity, such as bacteria, enzymes, food residues and so on [27]. Saliva reflects the systemic metabolic condition of blood [28,29], while oral fluid reflects the oral cavity condition [27].

In this work, we explore a new methodology to measure $\mathrm{HCN}$ simultaneously in the headspace of oral fluid and in mouth-exhaled breath of healthy volunteers. By combining the results of these two types of analyses, we seek to establish a direct correlation with the composition of breath and oral fluid. In addition, we hypothesize that the HCN concentration in oral fluid is related to the bacterial and enzymatic activity of the oral cavity. To test this hypothesis, we conducted oral disinfectant in vitro and in vivo tests.

\section{Materials and Methods}

\subsection{Human subjects and sampling}

Twenty five volunteers participated in the study. A written informed consent was obtained from all participating individuals. The research was approved by the Coordinating Ethics Committee of the Hospital District of Helsinki and Uusimaa. We conducted five tests with the volunteers: a sampling method, an inter-subject, an oral disinfectant in vitro and in vivo, and a cyanide spiking test. Three healthy volunteers took part in the sampling method test: two males and one female aged between 28 and 52. Samples were gathered at different times during the day between 8:30 and 16:00. In the intersubject test, a total number of 24 healthy volunteers participated: 18 males and 6 females aged between 22 and 64. The sampling time was between 9:00 and 12:20. The oral disinfectant in vitro and in vivo, and cyanide spiking tests were conducted with two volunteers: one male and one female aged between 28 and 37 . The sampling time for all the tests was at least two hours after the last meal. 
In the sampling method test, each volunteer gave a mouth-exhaled breath and a stimulated oral fluid sample. Sampling was performed as follows. The volunteer inhaled through the nose, exhaled through the mouth and filled an aluminium-coated 1.3 L sampling bag (Wagner Analysen Technik, WT 8004) with one exhalation. No attempt was made to extract the end-tidal part of the breath. The samples should therefore be considered mixed breath samples, i.e. including the "dead-space" contribution from the oral cavity and airways. Then, the volunteer chewed a piece of plastic paraffin film $(30 \mathrm{~mm} \times 30 \mathrm{~mm}$, Parafilm) for one minute. During the chewing, components in the oral cavity were mixed within the oral fluid. The volunteer kept the oral fluid in the oral cavity without swallowing it. After this one minute, all oral fluid was collected onto a plate. In total, we obtained 52 simultaneously stimulated oral fluid and mouth-exhaled breath samples. Each volunteer also gave an unstimulated oral fluid and mouth-exhaled breath sample. The unstimulated oral fluid refers to the oral fluid spit out by the volunteer without chewing a paraffin film. In total, we obtained 46 simultaneously unstimulated oral fluid and mouth-exhaled breath samples.

Twenty four volunteers were recruited for the inter-subject test. Sampling was performed in a similar fashion as in the sampling method test. Each volunteer was instructed to give a mouth-exhaled breath sample and a stimulated oral fluid sample. In total, we obtained 24 simultaneously mouthexhaled breath samples and stimulated oral fluid samples.

Corsodyl was used as a disinfectant in the oral disinfectant in vitro test. Corsodyl contains $0.2 \%$ of chlorhexidine digluconate and 96\% ethanol, and destroys most of the oral bacteria and inhibits enzyme activity for at least two hours [30]. Each volunteer was requested to give sublingual saliva and stimulated oral fluid samples. The sampling for sublingual saliva was performed as follows. The volunteer touched the back of the upper front teeth with the apex of tongue, tilted head forward and let the freshly secreted saliva flow out directly from the sublingual area into a tube or a plate. To eliminate the possibility of contamination by oral bacteria, the safest sampling technique seems to be to insert a tube directly into the sublingual area during sampling. The stimulated oral fluid sampling procedure was performed in a similar fashion as in the sampling method test. We prepared three tubes for the disinfectant in vitro test (table 1). The tubes were shaken for one minute to mix the oral fluid samples and the added solutions. The same protocol was repeated three times on two volunteers.

Table 1. Composition of the three test tubes in the disinfectant in vitro test.

\begin{tabular}{ccccc}
\hline Tube & Distilled $\mathrm{H}_{2} \mathrm{O}(\mu \mathrm{L})$ & Sublingual saliva $(\mu \mathrm{L})$ & Stimulated oral fluid $(\mu \mathrm{L})$ & Corsodyl $(\mu \mathrm{L})$ \\
\hline 1 & 200 & 300 & -- & -- \\
2 & 200 & -- & 300 & - \\
3 & -- & -- & 300 & 200 \\
\hline
\end{tabular}

In the oral disinfectant in vivo test, each volunteer was instructed to give four simultaneously mouth-exhaled breath samples and stimulated oral fluid samples before the disinfectant mouth rinse. The stimulated oral fluid samples were obtained in a similar fashion as in the sampling method test. Next, the volunteer rinsed her mouth for one minute, using $10 \mathrm{~mL}$ of the Corsodyl disinfectant. Immediately after the mouth rinse, the volunteer gave a mouth-exhaled breath and a stimulated oral fluid sample. Subsequent samples were taken after 30, 60, 90 and 120 minutes following the disinfectant mouth rinse.

In the cyanide spiking test, each volunteer was requested to give a stimulated oral fluid sample. Potassium cyanide $(\mathrm{KCN})$ was dissolved in distilled $\mathrm{H}_{2} \mathrm{O}$ to prepare the cyanide solution. Four tubes were prepared for this test (table 2). The tubes were shaken for one minute to mix the solutions. The same protocol was repeated three times on two volunteers. 
Table 2. Composition of the four test tubes in the cyanide spiking test.

\begin{tabular}{cccc}
\hline Tube & Distilled $\mathrm{H}_{2} \mathrm{O}(\mu \mathrm{L})$ & $25 \mu \mathrm{mol} / \mathrm{L} \mathrm{KCN}(\mu \mathrm{L})$ & Stimulated oral fluid $(\mu \mathrm{L})$ \\
\hline 1 & 250 & -- & -- \\
2 & 250 & 20 & -- \\
3 & -- & -- & 250 \\
4 & -- & 20 & 250 \\
\hline
\end{tabular}

\subsection{Hydrogen cyanide analysis}

2.2.1. Instrument. Cavity ring down spectroscopy (CRDS) was used for the detection and quantification of $\mathrm{HCN}$ in the gas phase. The spectrometer and data analysis procedures have been described in detail before [26].The wavenumber scanning range for the measurement was 6504.3$6504.5 \mathrm{~cm}^{-1}$. This includes absorption peaks for $\operatorname{HCN}\left(6504.412 \mathrm{~cm}^{-1}\right)$ and $\mathrm{CO}_{2}\left(6504.380 \mathrm{~cm}^{-1}\right)$. The temperature of the sample cell was stabilized at $37^{\circ} \mathrm{C}$. The measurement pressure in the cell was 50 Torr and 76 Torr for mouth-exhaled breath samples and oral fluid headspace samples, respectively. The HCN absorption peak overlaps with the $\mathrm{CO}_{2}$ absorption peak and consequently lower sample pressure was used for the breath samples to reduce spectral interference. Representative spectra for both types of samples are found in the supplementary material (available from XXX). The detection limit of the spectrometer for HCN was previously determined to be 300 pptv (two standard deviations) [26]. The instrumental precision of the measurement was estimated by measuring the standard deviation of ten bag samples. The obtained precision was 140 pptv (two standard deviations). The absolute accuracy was confirmed by comparative measurements with a commercial reference $\mathrm{HCN}$ gas standard, which was certified to within $10 \%$. Precision of the actual headspace and exhaled breath measurements is ultimately determined by the variance in the sampling. The sampling error is always larger than the instrumental error, and the magnitude of the error depends on the sampling technique that is employed.

2.2.2. Headspace measurement of $H C N$. The $\mathrm{pK}_{\mathrm{a}}$ value of cyanide is 9.3 . The normal $\mathrm{pH}$ range of saliva is 6.2-7.4 [31] and therefore $98-99 \%$ of cyanide is in the HCN form. According to Henry's law, HCN evaporates rapidly from liquid to gas phase. Hence, the headspace method can be used to measure the HCN concentration of oral fluid. Previous studies have used the static headspace method $[9,32,33]$. In our study, we measured the headspace HCN concentration of oral fluid directly in a flow. In addition, instead of using traditional solution headspace, we used cotton swabs as the oral fluid sample carriers. The large surface area of the cotton fibre enhances the HCN evaporation from oral fluid.

The headspace measurement was performed in the following fashion. A cotton swab was dipped into the sample solution to obtain $0.070-0.080 \mathrm{~g}$ of the solution. The cotton head of the swab was cut and placed in a $4 \mathrm{~mL}$ glass vial, which was connected to the CRDS spectrometer inlet tube. Ambient air flowed into the vial and HCN gas evaporated from the sample. HCN was delivered into the CRDS measurement cell with ambient air. The HCN concentration in ambient air is less than $0.3 \mathrm{ppb}$, which is considerably lower than the headspace $\mathrm{HCN}$ concentration of oral fluid. Hence, ambient air does not affect the HCN headspace measurements. The air flow rate was kept at $10 \mathrm{~mL} / \mathrm{min}$ using a mass flow controller. After $10 \mathrm{~min}$ of air flow, the observed HCN concentration signal became stable. This indicated that the gas/liquid interface in the sample vial has reached an equilibrium. At this point, the HCN spectrum was recorded.

To investigate the repeatability of the headspace measurement of HCN in oral fluid, we measured HCN concentration in two consecutive stimulated oral fluid samples. The sampling time between them was $15 \mathrm{~min}$. Every $30 \mathrm{~min}$, we measured another set of two consecutive stimulated oral fluid samples. Altogether, 17 pairs of samples were obtained. Two volunteers participated in the repeatability test. 
2.2.3. Measurement of mouth-exhaled HCN. To measure the HCN concentration from mouth-exhaled breath in the sampling bag, we connected the bag to the inlet tube of the CRDS spectrometer. A mass flow controller kept a flow of $500 \mathrm{~mL} / \mathrm{min}$ through the sample cell. After one minute of air flow, we closed the cell and adjusted the pressure to 50 Torr and started the HCN concentration measurement. Total measurement time was about four minutes. For experimental details, see Schmidt et al [26]. All the mouth-exhaled $\mathrm{HCN}$ values presented in this study are normalized by the $\mathrm{CO}_{2}$ concentration of the exhaled breath. Normalization of the target compound reduces the sampling variation among different subjects $[34,35]$. The normalization of mouth-exhaled $\mathrm{HCN}(\mathrm{HCN}$,norm) was calculated as in (1):

$$
\mathrm{HCNm}, \text { norm }(\mathrm{ppb})=\frac{\mathrm{HCN}_{\mathrm{m}}(\mathrm{ppb})}{\mathrm{CO}_{2}(\%)} \times 4.1(\%)
$$

The $4.1 \%$ multiplication factor is the mean $\mathrm{CO}_{2}$ concentration of the breath samples taken during the study.

\subsection{Statistical analysis}

Spearman's rank correlation test was used to analyze the correlations between oral fluid HCN and mouth-exhaled HCN. In this test, the $p$ value refers to the probability of obtaining the observation results, assuming the correlation coefficient was zero (null hypothesis), and $r_{s}$ is the correlation coefficient.

\section{Results}

\subsection{The repeatability test in the headspace measurement of oral fluid $H C N$}

In figure 1, the results of 17 sets of two consecutive headspace oral fluid measurements are plotted. HCN concentration of the first sample is plotted on the horizontal axis, while the HCN concentration of the second sample is plotted on the vertical axis. A least squares regression line was fitted to the data, and the intercept was set to zero. The slope of the equation is 0.88 and $\mathrm{R}^{2}$ is 0.91 . The limited repeatability in the headspace measurement is due to the difficulty in obtaining consistent oral fluid samples.

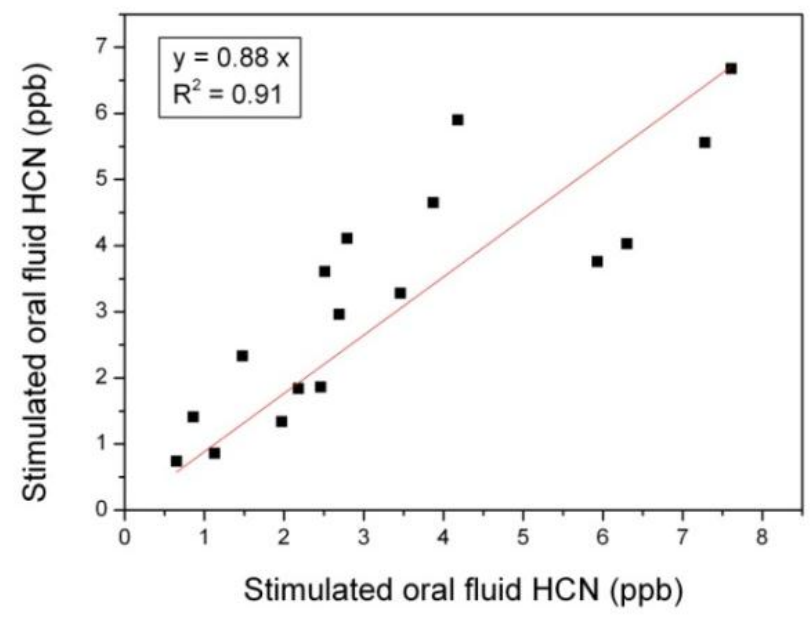

Figure 1. The repeatability test for the HCN measurement in the headspace of oral fluid. The solid line is a least squares fit to the data. 


\subsection{The sampling method and inter-subject test}

In the sampling method test, there is a correlation $\left(r_{s}=0.48, p<0.001\right)$ between unstimulated oral fluid $\mathrm{HCN}$ and mouth-exhaled HCN (figure 2a). However, there is a stronger correlation $\left(r_{s}=0.76, p<0.001\right.$ ) between stimulated oral fluid HCN and mouth-exhaled HCN (figure 2b). Consequently, we used stimulated oral fluid as the sampling method for the inter-subject test. In the inter-subject test $(\mathrm{n}=24)$, there is a correlation $\left(r_{s}=0.58, p=0.003\right)$ between stimulated oral fluid $\mathrm{HCN}$ and mouth-exhaled HCN (figure 3). Additionally, we observed a negative correlation between age and stimulated oral fluid HCN $\left(r_{s}=-0.45, p=0.03\right)$, but a similar correlation was not found between age and mouth-exhaled HCN.
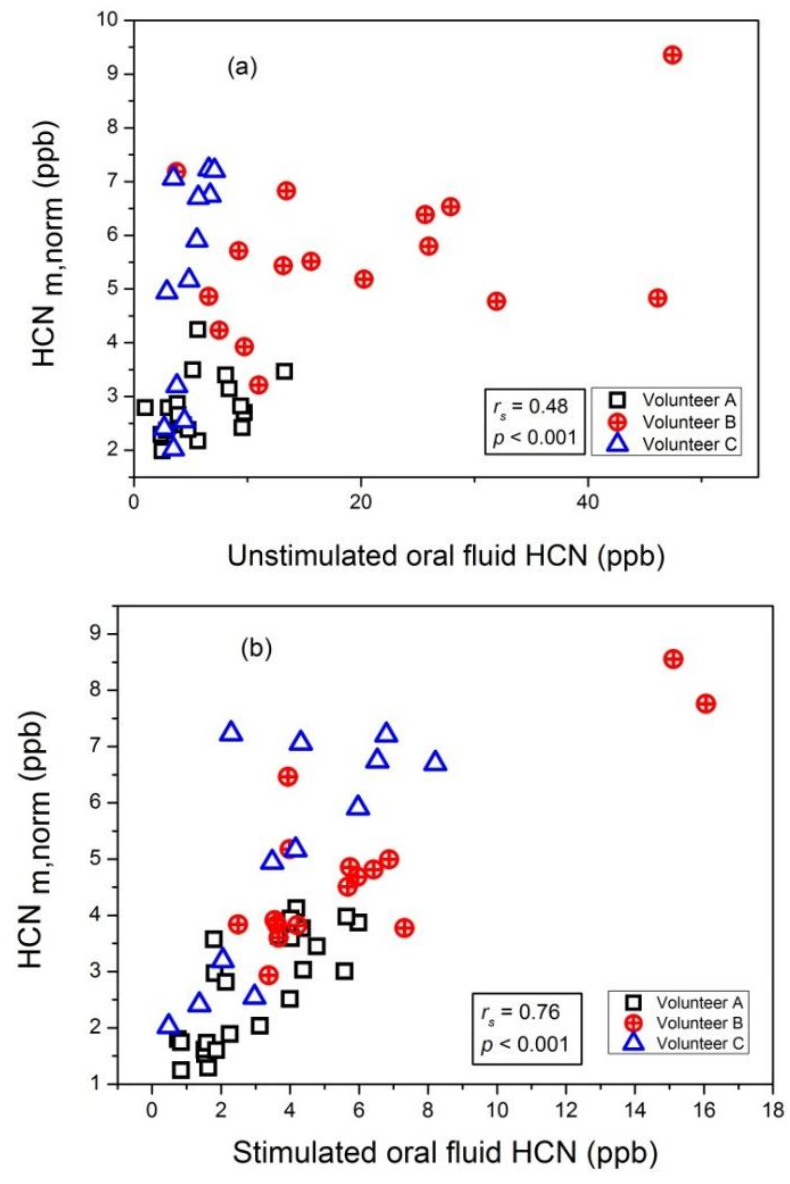

Figure 2. Correlation between unstimulated oral fluid HCN and mouth-exhaled HCN (a) and correlation between stimulated oral fluid HCN and mouth-exhaled HCN (b) in the sampling method test. 


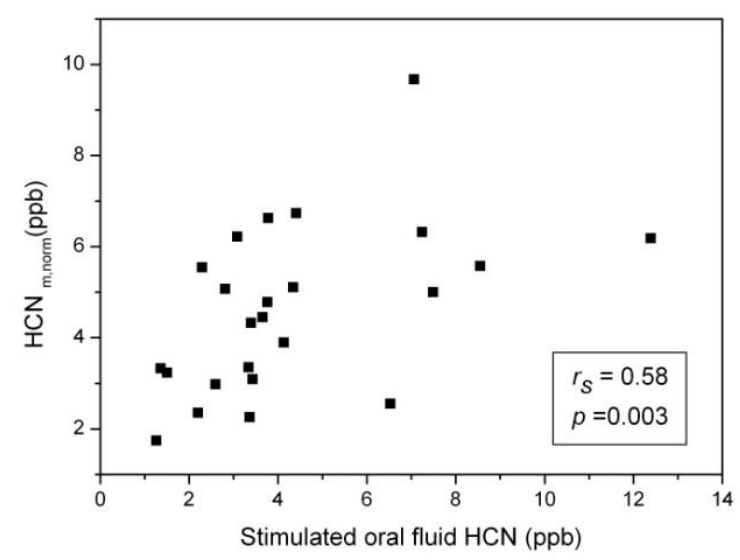

Figure 3. Correlation between stimulated oral fluid $\mathrm{HCN}$ and mouth-exhaled $\mathrm{HCN}$ in the inter-subject test.

\subsection{Oral disinfectant in vitro test}

Our results show that the HCN concentration in stimulated oral fluid (5.3 and $10.8 \mathrm{ppb}$ ) is higher than in sublingual saliva (1.2 and $3.7 \mathrm{ppb}$ ) in both volunteers (figure 4). After adding an oral disinfectant to inhibit bacterial and enzymatic activity, the HCN concentration decreases to 1.6 and $3.8 \mathrm{ppb}$ respectively, which are close to their HCN concentration in sublingual saliva.

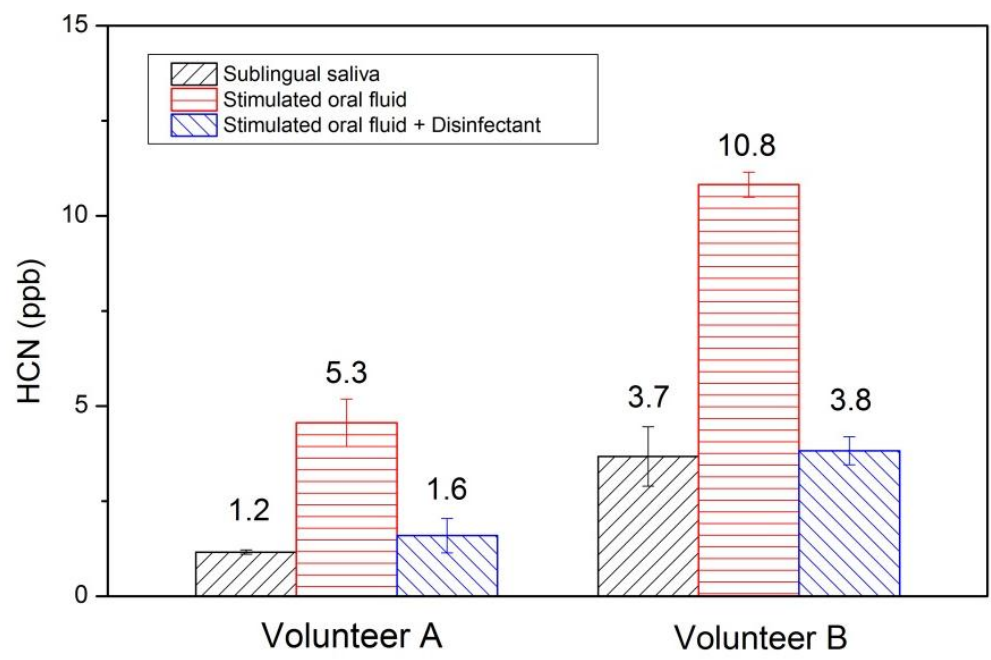

Figure 4. Headspace HCN concentration of three types of oral fluid samples. Data shown are mean values from three experiments. Error bars represent one standard deviation.

\subsection{Oral disinfectant in vivo test}

After the mouth rinse with an oral disinfectant, both the mouth-exhaled HCN and stimulated oral fluid HCN concentrations decrease significantly in both volunteers (figure 5). This indicates that oral fluid HCN levels have a major effect on mouth-exhaled HCN levels. The decrease of the HCN concentrations also implies that mouth-exhaled $\mathrm{HCN}$ levels are related to oral bacterial and enzymatic activity. 


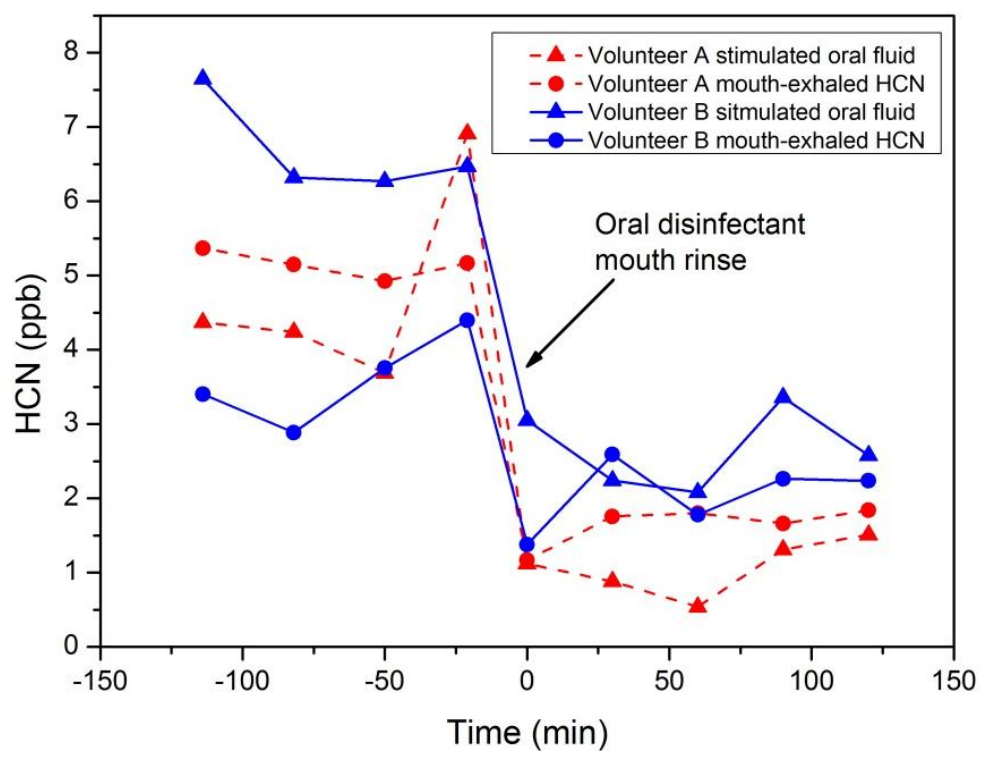

Figure 5. Disinfectant in vivo test. The symbol " $\mathbf{\Delta}$ " represents headspace HCN measurements of oral fluid. The symbol "•" represents HCN measurements of mouth-exhaled breath.

\subsection{Cyanide spiking test}

Our results demonstrate that the changes of the $\mathrm{HCN}$ concentration in spiked stimulated oral fluid in volunteer A (from 1.7 to $2.8 \mathrm{ppb}$ ) and volunteer B (from 4.0 to $3.7 \mathrm{ppb}$ ) are much smaller than in spiked distilled $\mathrm{H}_{2} \mathrm{O}$ (from 0.2 to $2.8 \mathrm{ppb}$ ) (figure 6). This indicates that a major part of the spiked cyanide is eliminated in stimulated oral fluid.

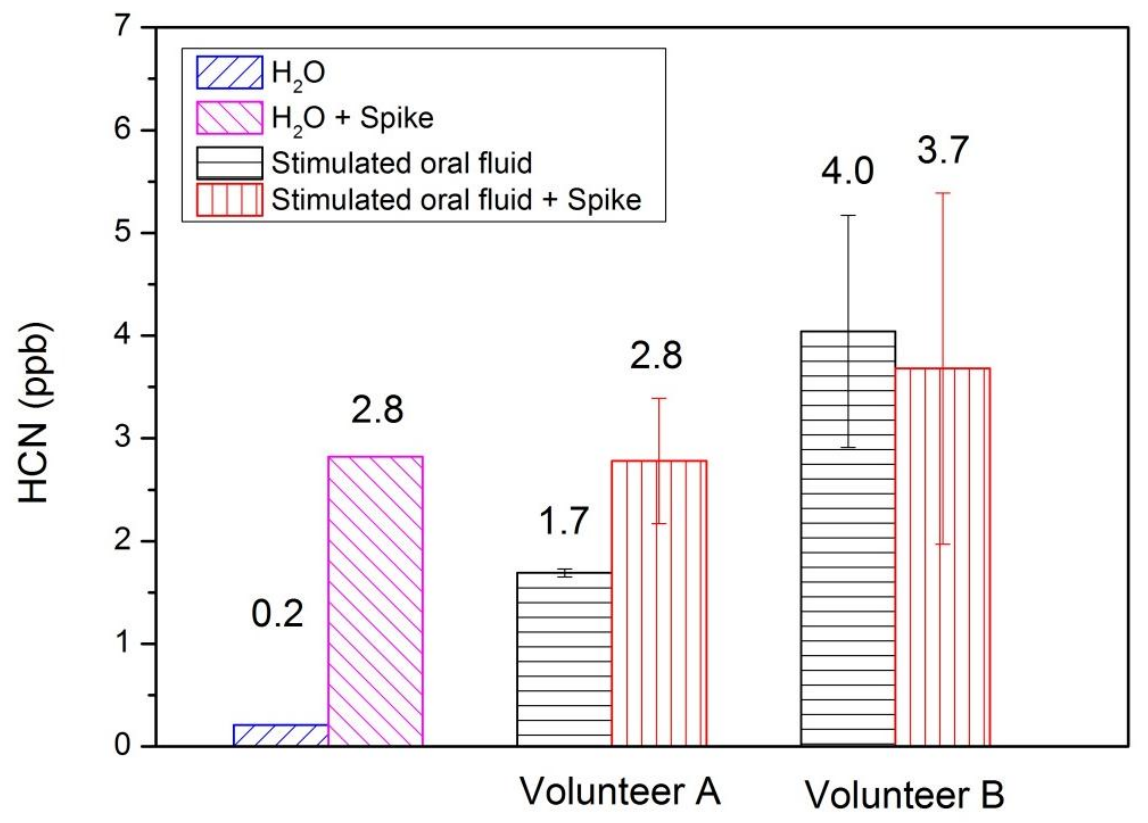

Figure 6. Cyanide spiking test in distilled $\mathrm{H}_{2} \mathrm{O}$ and stimulated oral fluid samples. Oral fluid data shown are mean values from three experiments. Error bars represent one standard deviation.

\section{Discussion}


The origin of mouth-exhaled HCN was first suggested to be oral fluid by Lundquist et al [11]. It has also been shown that mouth-exhaled HCN is mainly generated in the oral cavity [25]. Hence, we assumed that $\mathrm{HCN}$ in the headspace of oral fluid should be strongly correlated to mouth-exhaled HCN. In the sampling method test, the correlation between unstimulated oral fluid $\mathrm{HCN}$ and mouth-exhaled $\mathrm{HCN}$ is only moderate $\left(r_{s}=0.48, p<0.001\right)$. However, the correlation between stimulated oral fluid $\mathrm{HCN}$ and mouth-exhaled $\mathrm{HCN}$ is stronger $\left(r_{s}=0.76, p<0.001\right)$. This implies that the oral fluid sampling technique is crucial. The difference between stimulated oral fluid and unstimulated oral fluid is the chewing of a piece of paraffin film. After chewing, components of the entire oral cavity are mixed within the stimulated oral fluid. Thus, stimulated oral fluid HCN reflects the condition of the whole oral cavity. In contrast, unstimulated oral fluid sampling does not mix the different compartments of the oral cavity effectively and only partially reflects the condition of the oral cavity. This explains why mouth-exhaled $\mathrm{HCN}$ is correlated stronger to stimulated oral fluid $\mathrm{HCN}$ than to unstimulated oral fluid $\mathrm{HCN}$.

The coefficient of determination $\left(\mathrm{R}^{2}\right)$ in the sampling method test for stimulated oral fluid HCN vs. mouth-exhaled HCN is 0.58 , implying that stimulated oral fluid HCN only contributes to $58 \%$ of mouth-exhaled HCN. We believe that the low $\mathrm{R}^{2}$ value is mainly due to the variance in the oral fluid sampling. In the repeatability test (figure 1), we show that it is difficult to obtain highly consistent oral fluid samples. Although there is inadequacy in the oral fluid sampling technique, we still observe a statistically significant correlation between stimulated oral fluid HCN and mouth-exhaled HCN. This indicates that the new methodology, measurement of $\mathrm{HCN}$ in the headspace of oral fluid, gives consistent results with mouth-exhaled $\mathrm{HCN}$ measurements.

We further measured stimulated oral fluid $\mathrm{HCN}$ and mouth-exhaled $\mathrm{HCN}$ simultaneously in 24 volunteers. The result shows a moderate correlation $\left(r_{s}=0.58, p=0.003\right)$. There are two implications of this result. Firstly, measurement of HCN in the headspace of oral fluid could be used to approximately estimate the change of $\mathrm{HCN}$ concentration in mouth-exhaled breath. Secondly, the correlation coefficient $\left(r_{s}\right)$ in the inter-subject test is lower than the sampling method test, because the variation of the oral fluid sampling from different volunteers is larger. This further confirms that the oral fluid sampling technique is crucial in the oral fluid headspace measurement. The mean value of the mouthexhaled $\mathrm{HCN}$ without $\mathrm{CO}_{2}$ normalization in the inter-subject test is $3.9 \mathrm{ppb}$. The mean value measured previously in our laboratory for healthy adults using the same analysis technique was $6.6 \mathrm{ppb}$ [26]. Spanel et al have measured mouth-exhaled HCN from healthy children, young adults and senior volunteers using SIFT-MS. The results differ slightly between different age groups but the median values were always between $8-10 \mathrm{ppb}[21,22]$. The differences between the studies might be at least partially explained by the sampling techniques and the instructions given to the volunteers, leading to effectively different exhalation rates during sampling. Since HCN is mainly generated in the oral cavity, a higher exhalation flow rate could result in a lower exhaled HCN concentration.

In the oral disinfectant in vitro test, we found that after adding an oral disinfectant into stimulated oral fluid, the HCN concentration decreases rapidly. The oral disinfectant has been proven to inhibit the activity of bacteria and enzymes for at least two hours [30]. We believe that after adding the oral disinfectant, both oral bacteria and enzymes in stimulated oral fluid cease their activity and stop producing HCN. This leads to a considerable decrease of the headspace HCN concentration. The HCN concentration decreases to 1.6 and $3.8 \mathrm{ppb}$ in volunteer $\mathrm{A}$ and volunteer $\mathrm{B}$, respectively, which is close to their sublingual saliva headspace $\mathrm{HCN}$ concentration (1.2 and $3.7 \mathrm{ppb}$ ). Sublingual saliva is secreted freshly from the sublingual gland and is not normally contaminated by oral bacteria and enzymes [27]. We assume that sublingual saliva $\mathrm{HCN}$ represents the inherent salivary free cyanide, which is correlated to the systemic cyanide level. Most oral fluid HCN, however, is produced by oral bacteria or enzymatic activity. This confirms the assumption of Gilchrist et al, who hypothesized that oral hygiene affects mouth-exhaled HCN production [20]. Moreover, our results imply that a large part of the $\mathrm{HCN}$ that we measured in the headspace of the oral fluid is being actively produced by the sample during the measurement. 
Regarding the bacterial HCN production, $P$. aeruginosa is one of the likely candidates to produce $\mathrm{HCN}$ in the oral cavity. Previous studies have shown that $P$. aeruginosa produces $\mathrm{HCN}$ in vitro $[5,36-$ 38]. P. aeruginosa has also been found in the oral cavity of supposedly healthy volunteers [39]. Other bacteria could also produce HCN. For example, Lechner et al reported that Helicobacter pylori infection increases the level of mouth-exhaled HCN [40]. Concerning the enzymatic HCN production, it was proposed that cyanide is generated through the oxidation of thiocyanate $\left(\mathrm{SCN}^{-}\right)$by peroxidase [11]. However, other studies have shown that the oxidation of $\mathrm{SCN}^{-}$by peroxidase produces the hypothiocyanite ion $\left(\mathrm{OSCN}^{-}\right)$[41,42].

In the oral disinfectant in vivo test, we observed that after the mouth rinse with an oral disinfectant, mouth-exhaled HCN concentration decreases along with the oral fluid HCN concentration. The result not only confirms that mouth-exhaled HCN mainly comes from the oral cavity, but also explicitly shows that oral fluid $\mathrm{HCN}$ is the main contributor to mouth-exhaled HCN. One important implication of this result is that oral disinfectant has the ability to eliminate the production of $\mathrm{HCN}$ in the oral cavity. It has been suggested that if oral hygiene is maximized, mouth-exhaled HCN could still be used to diagnose $P$. aeruginosa infection in adults [20].

In the cyanide spiking test, we observed that the change of the headspace $\mathrm{HCN}$ concentration in spiked stimulated oral fluid is smaller than in spiked distilled $\mathrm{H}_{2} \mathrm{O}$. The change of $\mathrm{pH}$ after adding cyanide solution in distilled $\mathrm{H}_{2} \mathrm{O}$ is from 6.78 to 6.85 , and in oral fluid from 7.34 to 7.48. In this $\mathrm{pH}$ range, $98-99 \%$ of cyanide is in the $\mathrm{HCN}$ form and hence the change in $\mathrm{pH}$ cannot explain the change in the HCN concentration. The result indicates that stimulated oral fluid has the ability to eliminate the spiked cyanide. Previous studies have shown that cyanide present in the human body can be eliminated by cyanide detoxification mechanisms, such as enzymatic reaction with rhodanese [43] or conjugation with albumin $[8,44]$ and methemoglobin [45]. Albumin is found in oral fluid [46].

Based on the above results, we propose the following mechanism of $\mathrm{HCN}$ production in the oral cavity. In oral fluid, a minor fraction of HCN comes from inherent salivary free cyanide, which can be measured through sublingual saliva. This minor fraction of HCN relates to the systemic cyanide, which can be generated by e.g. neutrophils [6,7,47]. The major fraction of HCN in oral fluid, however, is produced by bacterial and enzymatic activity. The HCN concentration in the oral cavity is constantly regulated by the cyanide detoxification systems of the body. Eventually, the HCN in oral fluid evaporates into the gas phase and becomes mouth-exhaled HCN through breathing.

\section{Conclusion}

To our knowledge, this is the first study that combines mouth-exhaled breath analysis with simultaneous oral fluid analysis. Our results reveal a statistically significant correlation between stimulated oral fluid HCN and mouth-exhaled HCN. Through the headspace measurement, we confirm that cyanide oral production is most likely linked to bacterial and enzymatic activity. Furthermore, we show that the HCN concentration in oral fluid is actively regulated by a detoxification mechanism.

\section{Acknowledgments}

We thank all study participants. The authors would like to gratefully acknowledge the Academy of Finland for financial support.

\section{References}

[1] Labianca D A 1979 On the nature of cyanide poisoning J. Chem. Educ. 56 788-91

[2] Baum M M, Moss J A, Pastel S H and Poskrebyshev G A 2007 Hydrogen cyanide exhaust emissions from in-use motor vehicles Environ. Sci. technol. 41 857-62

[3] Symington I S, Anderson R A, Thomson I, Harland W A and Kerr J W 1978 Cyanide exposure in fires The Lancet 312 91-2

[4] Miller J M and Conn E E 1980 Metabolism of hydrogen cyanide by higher plants Plant Physiol. 65 1199-202 
[5] Blumer C and Haas D 2000 Mechanism, regulation, and ecological role of bacterial cyanide biosynthesis Arch. Microbiol. 173 170-7

[6] Stelmaszynska T 1985 Formation of HCN by human phagocytosing neutrophils--1. Chlorination of Staphylococcus epidermidis as a source of HCN Int. J. Biochem. 17 373-9

[7] Stelmaszynska T 1986 Formation of $\mathrm{HCN}$ and its chlorination to $\mathrm{ClCN}$ by stimulated human neutrophils--2. Oxidation of thiocyanate as a source of HCN Int. J. Biochem. 18 1107-14

[8] Lundquist P, Rosling H and Sorbo B 1985 Determination of cyanide in whole blood, erythrocytes, and plasma Clin. Chem. 31 591-5

[9] Tsuge K, Kataoka M and Seto Y 2000 Cyanide and thiocyanate levels in blood and saliva of healthy adult volunteers $J$. Health Sci. 46 343-50

[10] Ma J and Dasgupta P K 2010 Recent developments in cyanide detection: A review Anal. Chim. Acta 673 117-25

[11] Lundquist P, Rosling H and Sorbo B 1988 The origin of hydrogen cyanide in breath Arch. Toxicol. $61270-4$

[12] Koch C and Hoiby N 1993 Pathogenesis of cystic fibrosis Lancet 3411065

[13] Tramper-Stranders G A, van der Ent C K and Wolfs T F W 2005 Detection of Pseudomonas aeruginosa in patients with cystic fibrosis $J$. Cyst. Fibros. 4 37-43

[14] Kappler M, Kraxner A, Reinhardt D, Ganster B, Griese M and Lang T 2006 Diagnostic and prognostic value of serum antibodies against Pseudomonas aeruginosa in cystic fibrosis Thorax 61 684-8

[15] Smith D, Spanel P, Gilchrist F J and Lenney W 2013 Hydrogen cyanide, a volatile biomarker of Pseudomonas aeruginosa infection J. Breath Res. 7044001

[16] Carroll W, Lenney W, Wang T, Spanel P, Alcock A and Smith D 2005 Detection of volatile compounds emitted by Pseudomonas aeruginosa using selected ion flow tube mass spectrometry Pediatr. Pulmonol. 39 452-6

[17] Sanderson K, Wescombe L, Kirov S M, Champion A and Reid D W 2008 Bacterial cyanogenesis occurs in the cystic fibrosis lung Eur. Respir. J. 32 329-33

[18] Ryall B, Davies J C, Wilson R, Shoemark A and Williams H D 2008 Pseudomonas aeruginosa, cyanide accumulation and lung function in $\mathrm{CF}$ and non-CF bronchiectasis patients Eur. Respir. J. 32 740-7

[19] Enderby B, Lenney W, Brady M, Emmett C, Spanel P and Smith D 2009 Hydrogen Cyanide as a Biomarker for Pseudomonas Aeruginosa in the Breath of Children With Cystic Fibrosis Pediatr. Pulmonol. 44 142-7

[20] Gilchrist F J, Bright-Thomas R J, Jones A M, Smith D, Spanel P, Webb A K and Lenney W 2013 Hydrogen cyanide concentrations in the breath of adult cystic fibrosis patients with and without Pseudomonas aeruginosa infection J. Breath Res. 7026010

[21] Spanel P, Dryahina K and Smith D 2007 The concentration distributions of some metabolites in the exhaled breath of young adults J. Breath Res. 1026001

[22] Spanel P, Dryahina K and Smith D 2007 Acetone, ammonia and hydrogen cyanide in exhaled breath of several volunteers aged 4-83 years J. Breath Res. 1011001

[23] Enderby B, Lenney W, Brady M, Emmett C, Spanel P and Smith D 2009 Concentrations of some metabolites in the breath of healthy children aged 7-18 years measured using selected ion flow tube mass spectrometry (SIFT-MS) J. Breath Res. 3036001

[24] Stamyr K, Vaittinen O, Jaakola J, Guss J, Metsälä M, Johanson G and Halonen L 2009 Background levels of hydrogen cyanide in human breath measured by infrared cavity ring down spectroscopy Biomarkers 14 285-91

[25] Wang T, Pysanenko A, Dryahina K, Spanel P and Smith D 2008 Analysis of breath, exhaled via the mouth and nose, and the air in the oral cavity J. Breath Res. 2037013

[26] Schmidt F M, Metsälä M, Vaittinen O and Halonen L 2011 Background levels and diurnal variations of hydrogen cyanide in breath and emitted from skin J. Breath Res. 5046004

[27] Crouch D J 2005 Oral fluid collection: The neglected variable in oral fluid testing Forensic Sci. 
Int. 150 165-73

[28] Aps J K M and Martens L C 2005 Review: The physiology of saliva and transfer of drugs into saliva Forensic Sci. Int. 150 119-31

[29] Chiappin S, Antonelli G, Gatti R and De Palo E F 2007 Saliva specimen: A new laboratory tool for diagnostic and basic investigation Clin. Chim. Acta 383 30-40

[30] Cousido M C, Carmona I T, Garcia-Caballero L, Limeres J, Alvares M. and Diz P 2010 In vivo substantivity of $0.12 \%$ and $0.2 \%$ chlorhexidine mouthrinses on salivary bacteria Clin. Oral Invest. 14 397-402

[31] Schipper R G, Silletti E and Vingerhoeds M H 2007 Saliva as research material: Biochemical, physicochemical and practical aspects Arch. Oral Biol. 52 1114-35

[32] Seto Y 1996 Determination of physiological levels of blood cyanide without interference by thiocyanate Jpn. J. Toxicol. Environ. Health 42 319-25

[33] Jermak S, Pranaityte B and Padarauskas A 2006 Headspace single-drop microextraction with indrop derivatization and capillary electrophoretic determination for free cyanide analysis Electrophoresis 27 4538-44

[34] Niu H C, Schoeller D A and Klein P D 1979 Improved gas chromatographic quantitation of breath hydrogen by normalization to respiratory carbon dioxide J. Lab. Clin. Med. 94 755-63

[35] Cope K A, Watson M T, Foster W M, Sehnert S S and Risby T H 2004 Effects of ventilation on the collection of exhaled breath in humans J. Appl. Physiol. 96 1371-9

[36] Gilchrist F J, Alcock A, Belcher J, Brady M, Jones A, Smith D, Spanel P, Webb K and Lenney W 2011 Variation in hydrogen cyanide production between different strains of Pseudomonas aeruginosa Eur. Respir. J. 38 409-14

[37] Gilchrist F J, Sims H, Alcock A, Belcher J, Jones A M, Smith D, Spanel P, Webb A K and Lenney W 2012 Quantification of hydrogen cyanide and 2-aminoacetophenone in the headspace of Pseudomonas aeruginosa cultured under biofilm and planktonic conditions Anal. Methods 4 3661-5

[38] Arslanov D D, Castro M P P, Creemers N A, Neerincx A H, Spunei M, Mandon J, Cristescu S M, Merkus P and Harren F J M 2013 Optical parametric oscillator-based photoacoustic detection of hydrogen cyanide for biomedical applications J. Biomed. Opt. 18107002

[39] Jain K, Parida S, Mangwani N, Dash H R and Das S 2013 Isolation and characterization of biofilm-forming bacteria and associated extracellular polymeric substances from oral cavity Ann. Microbiol. 1-10

[40] Lechner M, Karlseder A, Niederseer D, Lirk P, Neher A, Rieder J and Tilg H 2005 H. pylori Infection Increases Levels of Exhaled Nitrate Helicobacter 10 385-90

[41] Aune T M and Thomas E L 1977 Accumulation of hypothiocyanite ion during peroxidasecatalyzed oxidation of thiocyanate ion Eur. J. Biochem. 80 209-14

[42] Wijkstrom-Frei C, El-Chemaly S, Ali-Rachedi R, Gerson C, Cobas M A, Forteza R, Salathe M and Conner G E 2003 Lactoperoxidase and human airway host defense Am. J. Respir. Cell And Mol. Biol. 29 206-12

[43] Billaut-Laden I, Allorge D, Crunelle-Thibaut A, Rat E, Cauffiez C, Chevalier D, Houdret N, Lo-Guidice J and Broly F 2006 Evidence for a functional genetic polymorphism of the human thiosulfate sulfurtransferase (Rhodanese), a cyanide and H2S detoxification enzyme Toxicology 225 1-11

[44] Fasco M J, Hauer C R, Stack R F, O'Hehir C, Barrón J R and Eadon G A 2007 Cyanide Adducts with Human Plasma Proteins: Albumin as a Potential Exposure Surrogate Chem. Res. Toxicol. 20 677-84

[45] McMillan D E and Svoboda A C 1982 The role of erythrocytes in cyanide detoxification $J$. Pharmacol. Exp. Ther. 221 37-42

[46] Henskens Y M C, Velden U, Veerman E C I and Amerongen A V N 1993 Protein, albumin and cystatin concentrations in saliva of healthy subjects and of patients with gingivitis periodonitis J. Periodontal Res. 28 43-8 
[47] Dummer J, Storer M, Sturney S, Scott-Thomas A, Chambers S, Swanney M and Epton M 2013 Quantification of hydrogen cyanide $(\mathrm{HCN})$ in breath using selected ion flow tube mass spectrometry- $\mathrm{HCN}$ is not a biomarker of Pseudomonas in chronic suppurative lung disease J. Breath Res. 7017105 